\title{
EFFECT OF THE VARIABLE GEAR MESH MODEL IN DYNAMIC SIMULATION OF A DRIVE TRAIN IN THE WIND TURBINE
}

\author{
Yonghui Park ${ }^{1 *}$ - Wei Shi ${ }^{2}-$ Hyunchul Park ${ }^{3}$ \\ ${ }^{1}$ Department of Mechanical Engineering Mechanical System Major, Yuhan College, Bucheon, Republic of Korea \\ ${ }^{2}$ State Key Laboratory of Coastal and Offshore Engineering, Dalian University of Technology, Dalian, China \\ ${ }^{3}$ Graduate School of Engineering Mastership, POSTECH, Pohang, Republic of Korea
}

\begin{tabular}{|c|c|}
\hline ARTICLE INFO & Abstract: \\
\hline $\begin{array}{l}\text { Article history: } \\
\text { Received: } 2.8 .2019 . \\
\text { Received in revised form: } \\
\text { Accepted: } 8.1 .2020 .\end{array}$ & $\begin{array}{l}\text { To acquire transient response of a drive train, we consider more } \\
\text { detailed mathematical model including variable gear mesh. The } \\
\text { gear mesh is represented by the Fourier series. In transient } \\
\text { analysis, gear's angular velocity is considered as constant. It }\end{array}$ \\
\hline $\begin{array}{l}\text { Keywords: } \\
\text { Drive train } \\
\text { Variable gear mesh } \\
\text { Dynamics \& Vibrations } \\
\text { Fourier transform }\end{array}$ & $\begin{array}{l}\text { makes sense when we consider steady-state. However, the gear } \\
\text { mesh is the only part which vary according to angular } \\
\text { displacement. It should be considered not only by the Fourier } \\
\text { series model but also as a modified system displacement. To } \\
\text { establish the gear mesh model, we use a curve fitting theorem. }\end{array}$ \\
\hline DOI: https://doi.org/10.30765/er.1496 & $\begin{array}{l}\text { Equations of motion are derived by the Lagrange's equation, } \\
\text { constrained equation and gear relation. The equations are solved } \\
\text { by numerical integration method, the Newmark method. Through } \\
\text { these processes, we get dynamic results including angular } \\
\text { displacement, velocity, acceleration, gear mesh contact forces. } \\
\text { Also, the Fourier transform is used to see signals more detailed. } \\
\text { At last, we compared the variable gear mesh and constant gear } \\
\text { mesh, gave physical meaning, and analyzed cause of the } \\
\text { phenomenon. }\end{array}$ \\
\hline
\end{tabular}

\section{Introduction}

The wind turbine systems are moving from land to sea to ensure high energy efficiency. Especially, it is spurring on the development of a floating system on the sea, coupling with the floating body instead of the installation of the jacket type fixed wind power generator, for installation in the deep sea where the wind resources are abundant. Hywind, an offshore wind turbine complex, jointly developed by Masdar and Startoil, was the first demonstration project to solve various problems such as vibration, noise and radio interference which are major drawbacks in existing wind power generators.

However, as the degree of freedom increases at the foundation of the wind power generator and the external force due to environmental conditions increases, many vibrations are generated, which makes analysis of the dynamic characteristics of the wind power system more important. In the analysis of the rotational dynamic characteristics of the drive train, a mathematical model capable of analyzing the steady state is developed. It is difficult to analyze the transient state when the operation or interruption of the wind turbine or various external forces act.

Therefore, it is necessary to utilize the mathematical model to identify the cause of the specific vibration in the operation process by considering the geometrical characteristics of the mechanical parts in the existing mathematical model.

In this research, we considered torsional drive train model that has the gear mesh model. In the previous research, the torsional and 3 dimensional model which has steady gear mesh $[1,2]$ and more detailed 3

\footnotetext{
* Corresponding author

E-mail address: yhpark@yuhan.ac.kr
} 
dimensional model which considered bending stiffness of shaft and translational stiffness of bearing [3] were modeled.

The research analyzed the dynamic responses of the rotors according to the gear mesh force in the timefrequency domain. However, the research assumed that gear mesh is determined by constant angular velocity for steady state. Using these results, we can find repeated vibrations. However, it is not useful in view of general motion. Actually, the gear mesh model is affected by not only defined concept but also system displacement. And there is a limit to express relationship between mechanical components using repeated assumption in coupled dynamics. Through these facts, it is necessary to consider variable system definitions especially gear mesh. In order words, we need to improve the mathematical model to do transient analysis. It can show instantaneous dynamic results.

To represent variable gear mesh, we used the curve fitting theorem to define gear mesh as a function. We also rearranged the gear mesh data from time domain to angular displacement especially carrier, gear 1, gear 3. Regarding an equation of motion, the Lagrange's equation was used with constraints equation and gear relationship. Mathematical model is composed of a non-linear term. So, it is hard to get analytical solution. Using the Newmark method, we obtained the numerical solution, compared to constant gear mesh model, and analyzed vibrations, phenomenon.

\section{Mathematical model}

\subsection{Gear mesh}

Before defining a variable gear mesh model, basic gear mesh model should be established from the previous work. Generally, gear mesh stiffness can be established by the Fourier series with constant angular velocity. Stiffness will be determined by angle of attack and contact ratios. [1,2,4] Through these facts, we defined the gear mesh stiffness using gear angular velocity and contact ratio. To generate stiffness model, we used rotor's angular velocity, $6 \mathrm{rpm}$, as reference. So, an average angular velocity in the planetary stage and parallel stages were defined by equation (1), (2), (3). And using the Fourier series, we established the gear mesh stiffness Equation (4), (5).

$$
\begin{gathered}
\omega_{M}^{(P)}=\omega_{C} N_{r} \\
\omega_{M}^{(g 12)}=\omega_{g 1} N_{g 1} \\
\omega_{M}^{(g 34)}=\omega_{g 3} N_{g 3} \\
k_{s p}(t)=k_{s p}+\frac{k_{s p}}{C_{s p}} \sum_{l=0}^{\infty}\left(a_{s p}^{(l)} \sin \left(\omega_{M}^{(p)} t\right)+b_{s p}^{(l)} \cos \left(\omega_{M}^{(p)} t\right)\right) \\
k_{r p}(t)=k_{r p}+\frac{k_{r p}}{C_{r p}} \sum_{l=0}^{\infty}\left(a_{r p}^{(l)} \sin \left(\omega_{M}^{(p)} t\right)+b_{r p}^{(l)} \cos \left(\omega_{M}^{(p)} t\right)\right) \\
a_{s p}^{(l)}=-\frac{2}{l \pi} \sin \left[l \pi\left(C_{s p}-2 \gamma_{s p}\right)\right] \sin \left(l \pi C_{s p}\right) \\
b_{s p}^{(l)}=-\frac{2}{l \pi} \cos \left[l \pi\left(C_{s p}-2 \gamma_{s p}\right)\right] \sin \left(l \pi C_{s p}\right) \\
a_{r p}^{(l)}=-\frac{2}{l \pi} \sin \left[l \pi\left(C_{s p}-2 \gamma_{s p}-2 \gamma_{r s}\right)\right] \sin \left(l \pi C_{r p}\right) \\
b_{r p}^{(l)}=-\frac{2}{l \pi} \cos \left[l \pi\left(C_{r p}-2 \gamma_{r p}-2 \gamma_{r s}\right)\right] \sin \left(l \pi C_{r p}\right)
\end{gathered}
$$

As shown, these stiffness models are function of time variable. It means that gear mesh stiffness will not change by other system variables. Actually, gear mesh stiffness is affected by angular displacement, velocity. 
This is because gear mesh stiffness is determined by gear's rotation and geometry. So, It should be considered not only in time, but also in displacement.

To represent gear mesh stiffness according to displacement, we defined gear mesh stiffness as a function of displacement. In the basic model, we used constant angular velocity. Using this angular velocity, we rearranged the gear mesh model according to angular displacement as input domain. In other words, input, output variables are angular displacement, gear mesh stiffness. Using this data, we can determine the gear mesh function. Curve fitting is deriving representative mathematical model to express given data. There is a lot of expression, including polynomial, exponential, Fourier and so on. In this research, we selected the Fourier curve fitting method because we used it in defining gear mesh stiffness. Equation (6) is the 8th Fourier series expression which we used.

$$
\begin{aligned}
f(x)= & a_{0}+a_{1} \cos (\omega x)+b_{1} \sin (\omega x) \\
& +a_{2} \cos (\omega x)+b_{2} \sin (\omega x) \\
& +\ldots+a_{8} \cos (\omega x)+b_{8} \sin (\omega x)
\end{aligned}
$$

The advantage of the function is that it is easy to represent output when input variable is not steady or regular. In the drive-train system, there is a phase difference because of coupled motion especially caused by shaft torsional displacement. As a result, phase affects differently angular displacement and velocity. It means that gear mesh stiffness should be variable, not a steady gear mesh model.

Through these processes, we derived to the gear mesh stiffness model regarding the drive-train. Figure 1 is example of gear mesh stiffness in a real drive-train system. As shown in Figure 1, gear mesh stiffness is not regular. It shows that the changes of gear mesh stiffness go fast as component's angular velocity go fast.

\subsection{Equation of Motion using torsional dynamics}

As presented in Figure 2, the wind turbine drive train was modeled rotor, carrier, planetary stage, parallel stages, and generator. [5-12] Each component was considered rigid body. There are three main shafts which exist between rotor and carrier, sun gear and gear 1, gear 3 and generator. System properties including moment of inertia, mass and stiffness were referred according to the previous research [1]. Equation of motion is represented by mass, stiffness, and damping matrix. Especially, mass matrix, stiffness matrix is related to each moment of inertia, mass and relative displacement of two points that are connected by stiffness.
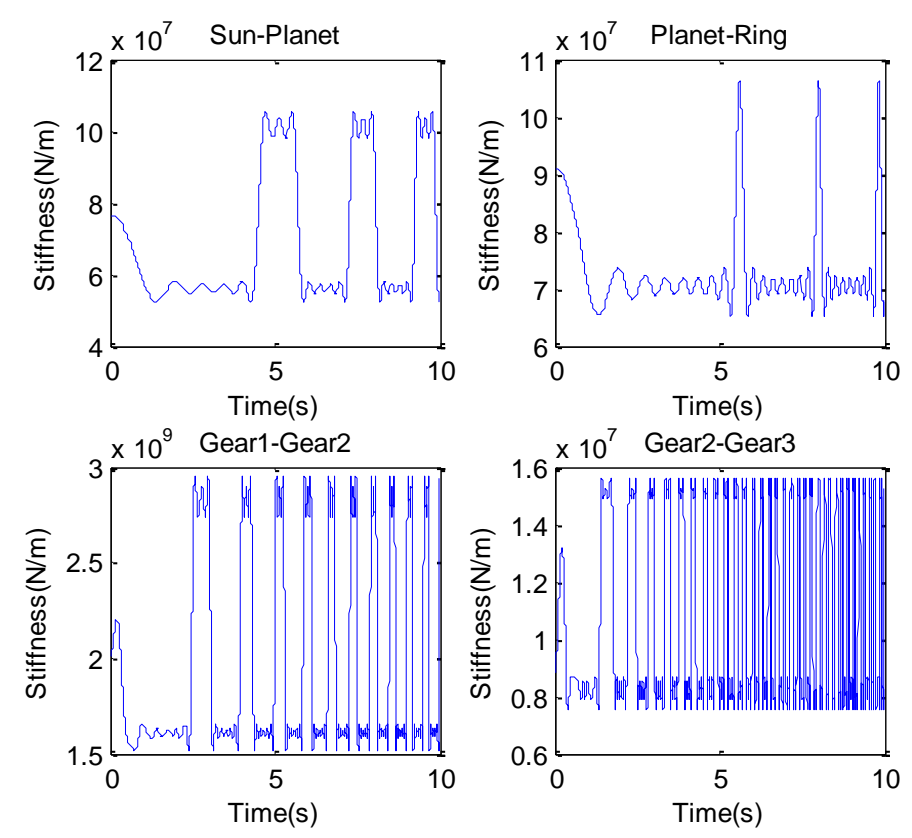

Figure 1. Gear mesh stiffness model. 


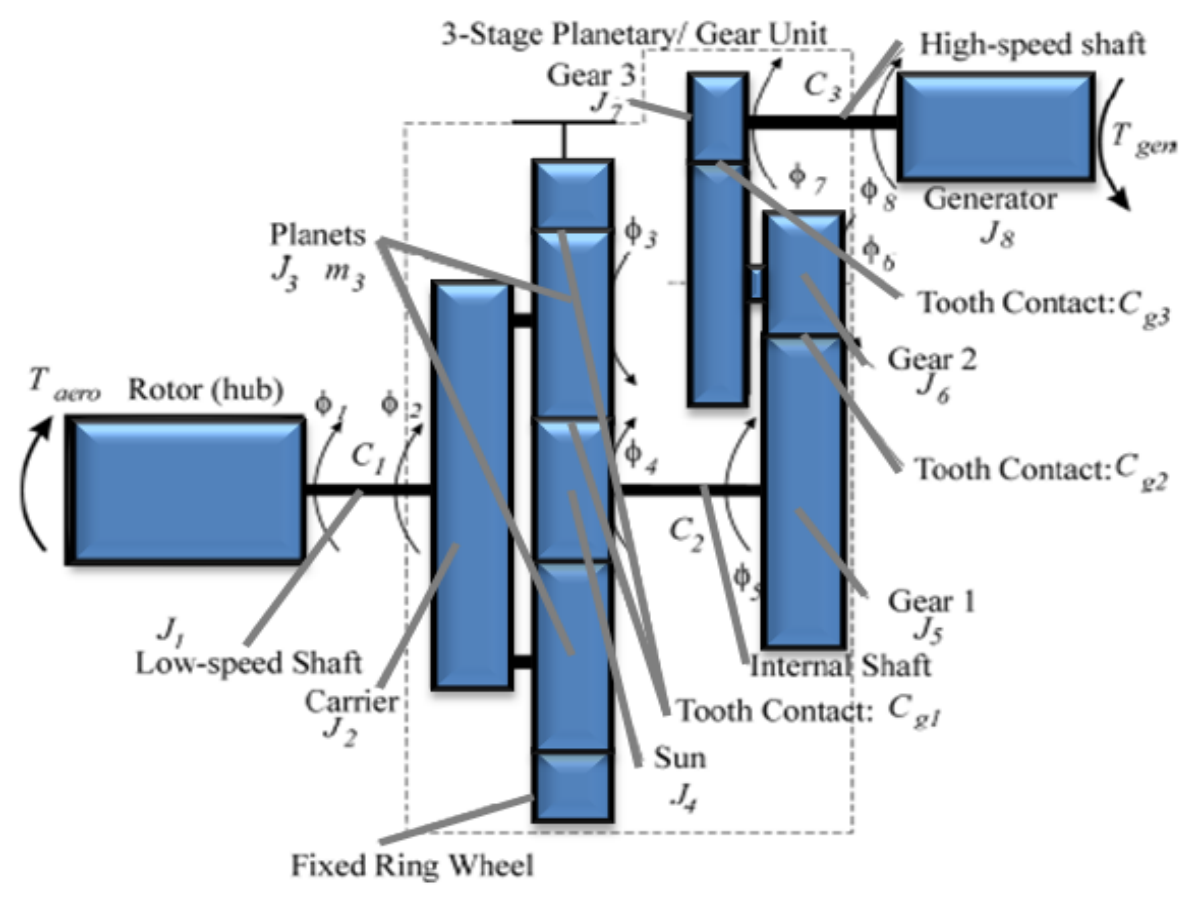

Figure 2. Mathematical model of wind turbine drive-train.

To derive motion of equation, the Lagrange's equation method was used. [13] It is more efficient using the Lagrange's equation in the constrained system. This is because the number of generalized coordinates is smaller than the Newton's method. In defining system properties, gear mesh stiffness will change in every time. So we reflected these change in the stiffness matrix. Sometimes, singularity problem happens because of mass, stiffness matrix components position and values. At deriving matrix using the Lagrange's equation, the fact that the entire matrix is symmetrical should be checked.

Regarding relative displacement, examples of rotation and translation about z-axis in Equations (7)-(13) were shown.

$$
\begin{gathered}
\phi_{L S S}=\phi_{\text {rotor }}-\phi_{\text {carrier }} \\
\delta_{\text {planet-sun }}=-r_{\text {carrier }} \phi_{\text {carrier }}+r_{\text {planet }} \phi_{\text {planet }}+r_{\text {sun }} \phi_{\text {sun }} \\
\delta_{\text {planet-ring }}=r_{\text {carrier }} \phi_{\text {carrier }}+r_{\text {planet }} \phi_{\text {planet }} \\
\phi_{I S}=\phi_{\text {sun }}-\phi_{G 1} \\
\delta_{G 1-G 2}=r_{G 1} \phi_{G 1}+r_{G 2} \phi_{G 2} \\
\delta_{G 2-G 3}=r_{G 2} \phi_{G 2}+r_{G 3} \phi_{G 3} \\
\phi_{H S S}=\phi_{G 3}-\phi_{G N}
\end{gathered}
$$

Equations (14), (15) are total kinetic, potential energies in the system. We substituted relative displacement into potential energy terms. 


$$
\begin{aligned}
\mathrm{T}= & \frac{1}{2} J_{r_{z}}\left(\dot{\phi} r_{r}\right)^{2}+\frac{1}{2} J_{c_{z}}\left(\dot{\phi_{c}}\right)^{2}+\frac{3}{2} m_{p}\left(r_{c} \dot{\phi}_{c}\right)^{2}+\frac{3}{2} J_{p_{z}}\left(\dot{\phi_{p}}\right)^{2} \\
+ & \frac{1}{2} J_{s_{z}}\left(\dot{\phi_{s}}\right)^{2}+\frac{1}{2} J_{g 1_{z}}\left(\dot{\phi}_{g 1}\right)^{2}+\frac{1}{2} J_{g 2_{z}}\left(\dot{\phi}_{g 2}\right)^{2}+\frac{1}{2} J_{g 3_{z}}\left(\dot{\phi}_{g 3}\right)^{2} \\
+ & \frac{1}{2} J_{G N_{z}}\left(\dot{\phi}_{G N}\right)^{2} \\
\mathrm{~V}= & \frac{1}{2} k_{L S S_{z}}\left(\phi_{L S S}\right)^{2}+\frac{1}{2} k_{I S_{z}}\left(\phi_{I S}\right)^{2}+\frac{1}{2} k_{H S S_{z}}\left(\phi_{H S S}\right)^{2} \\
& +\frac{3}{2} k_{r p}\left(\delta_{\text {planet-ring }}\right)^{2}+\frac{3}{2} k_{s p}\left(\delta_{\text {planet-sun }}\right)^{2} \\
& +\frac{1}{2} k_{g 12}\left(\delta_{G 1-G 2}\right)^{2}+\frac{1}{2} k_{g 34}\left(\delta_{G 2-G 3}\right)^{2}
\end{aligned}
$$

Using kinetic, potential energy terms, we can derive to the Lagrange's equation and equation of motion. Equations (16)-(18) are the process of determination motion of equation. Q vector is generalized forces including gravity and external force.

$$
L=T-V
$$

( $T$ : kinetic energy, $V$ : potential energy)

$$
\begin{gathered}
\frac{d}{d t}\left(\frac{\delta L}{\delta q_{j}}\right)-\frac{\delta L}{\delta q_{j}}=Q_{j} \quad \mathrm{j}=1,2,3 \ldots 36 \\
\text { where }\left(Q_{j}=Q_{g}(t)+Q_{\text {ext }}(t)\right) \\
{[J] \ddot{\vec{\phi}}+[C] \dot{\vec{\phi}}+[K] \vec{\phi}=Q_{j}}
\end{gathered}
$$

\subsection{Numerical Analysis}

If equation of motion cannot be integrated as closed form, it is difficult to get analytical solution. [14-16] Numerical analysis is approximated solution using assumptions. There are lots of numerical integration methods. We can use different numerical integration methods according to the governing equation. There are two main characteristics in numerical integration. First, the Numerical integration methods don't satisfy the time region. It is designated to satisfy divided time region $\Delta \mathrm{t}=\mathrm{T} / \mathrm{n}$. Second, there are assumptions specifying reasonable displacement, velocity, acceleration in $\Delta \mathrm{t}$ region. Through these assumptions, we can classify numerical integration methods. Generally, initial displacement and velocity are known. The aim of the numerical method is getting responses from the start time 0 to the end time $\mathrm{T}$.

The Numerical integration method can be divided into explicit method and implicit method. Implicit methods include finite differential method and Runge-kutta determine present response using the Taylor series equation or modified equation with previous response. However, there is error and divergence possibility because it doesn't consider motion of equation. Per contra, implicit methods including Houbolt, Wilson and Newmark method use motion of equation with previous responses when we solve differential equation. This method can be applied multi-degree of freedom system and non-linear system.

According to these facts, we chose the Newmark method to solve equation of motion. The Newmark integration method assumes the accelerations between consequent times. Through this assumption, $\mathrm{t}+\Delta \mathrm{t}$ of displacement and velocity of $\mathrm{t}+\Delta \mathrm{t}$ can be determined equation (19), (20)

$$
\dot{u}_{t+\Delta t}=\dot{u}_{t}+\left[(1-\beta) \ddot{u}_{t}+\beta \ddot{u}_{t+\Delta t}\right] \Delta t
$$




$$
u_{t+\Delta t}=u_{t}+\Delta t \dot{u}_{t}+\left[\left(\frac{1}{2}-\alpha\right) \ddot{u}_{t}+\alpha \ddot{u}_{t+\Delta t}\right](\Delta t)^{2}
$$

The parameters $\alpha, \beta$ represent that how acceleration of end time $\mathrm{T}$ affect velocity and displacement of end time $\Delta \mathrm{t}$. To satisfy stability and accuracy, we can select parameters value. The sets which $\alpha=1 / 6, \beta=1 / 2$ are same as linear acceleration method. In this research, we chose the sets which $\alpha=1 / 4, \beta=1 / 2$. It means that the response is a constant acceleration between $\mathrm{t}$ and $\mathrm{t}+\Delta \mathrm{t}$.

$$
M \ddot{u}_{t+\Delta t}+C \dot{u}_{t+\Delta t}+K u_{t+\Delta t}=Q_{t+\Delta t}
$$

Equation (21) is motion of equation at $\mathrm{t}+\Delta \mathrm{t}$. By using substituting (20), $\ddot{u}_{t+\Delta t}$ can be arranged into $\mathrm{u}_{\mathrm{t}+\Delta \mathrm{t}}$. And, substituting it into (19), we can arrange $\dot{u}_{t+\Delta t}$ into $\mathrm{u}_{\mathrm{t}+\Delta \mathrm{t}}$. Finally, we have equation $\ddot{u}_{t+\Delta t}$ and $\dot{u}_{t+\Delta t}$ which are represented in $u_{t+\Delta t}$. Through this results, we can determine $u_{t+\Delta t}$ by substituting these equations into (21).

$$
\begin{aligned}
u_{t+\Delta t}=[ & \left.\frac{1}{\alpha(\Delta t)^{2}}[M]+\frac{\beta}{\alpha(\Delta t)}[C]+[K]\right]^{-1} \\
& \times\left\{Q_{t+\Delta t}+[M]\left(\frac{1}{\alpha(\Delta t)^{2}} u_{t}+\frac{1}{\alpha(\Delta t)} \dot{u}_{t}+\left(\frac{1}{2 \alpha}-1\right) \ddot{u}_{t}\right)\right. \\
& \left.+[C]\left(\frac{\beta}{\alpha(\Delta t)} u_{t}+\left(\frac{\beta}{\alpha}-1\right) \dot{u}_{t}+\left(\frac{\beta}{\alpha}-2\right) \frac{\Delta t}{2} \ddot{u}_{t}\right)\right\}
\end{aligned}
$$

Equation (22) is $\mathrm{u}_{\mathrm{t}+\Delta \mathrm{t}}$. As referred, we can determine $\ddot{u}_{t+\Delta t}$ and $\dot{u}_{t+\Delta t}$ as Equations (23) and (24)

$$
\begin{gathered}
\ddot{u}_{t+\Delta t}=\frac{1}{\alpha(\Delta t)^{2}}\left(u_{t+\Delta t}-u_{t}\right)-\frac{1}{\alpha(\Delta t)} \dot{u}_{t}-\left(\frac{1}{2 \alpha}-1\right) \ddot{u}_{t} \\
\dot{u}_{t+\Delta t}=\dot{u}_{t}+(1-\beta) \Delta t \ddot{u}_{t}+\beta \Delta t \ddot{u}_{t \Delta t}
\end{gathered}
$$

\subsection{Simulation}

Table 1 [3] shows basic information about the drive train. It was assumed that the aerodynamic torque is $\mathrm{T}_{\text {aero }}=15000 \mathrm{Nm}$, and electromagnetic torque is $-30 \%$ of aerodynamic torque which correspond $30 \%$ wind turbine efficient.

\section{Results and discussion}

\subsection{Angular displacement comparison between variable gear mesh and steady gear mesh}

There is no difference of end angular displacement values between variable gear mesh and steady gear mesh. In addition, general shape of angular displacement is similar, we cannot notify difference. However, not like regular vibration phenomenon. It has irregular pattern of difference. Figure 3 shows angular displacement difference between the two gear models. 
Table 1. Data for the drivetrain configuration.

\begin{tabular}{|c|c|}
\hline Parameter & Value \\
\hline $\mathrm{J}_{\mathrm{rz}}-$ inertia of the rotor $\left(\mathrm{kg} \cdot \mathrm{m}^{2}\right)$ & $4.18 \cdot 10^{6}$ \\
\hline $\mathrm{J}_{\mathrm{cz}}-$ inertia of the carrier $\left(\mathrm{kg} \cdot \mathrm{m}^{2}\right)$ & 57.72 \\
\hline $\mathrm{J}_{\mathrm{pz}}-$ inertia of the planet $\left(\mathrm{kg} \cdot \mathrm{m}^{2}\right)$ & 1.12 \\
\hline $\mathrm{J}_{\mathrm{sz}}-$ inertia of the sun $\left(\mathrm{kg} \cdot \mathrm{m}^{2}\right)$ & 0.86 \\
\hline $\mathrm{J}_{\mathrm{g} 1 \mathrm{z}}-$ inertia of the gear $1\left(\mathrm{~kg} \cdot \mathrm{m}^{2}\right)$ & 14.32 \\
\hline $\mathrm{J}_{\mathrm{g} 2 \mathrm{z}}-$ inertia of the gear $2\left(\mathrm{~kg} \cdot \mathrm{m}^{2}\right)$ & 1.62 \\
\hline $\mathrm{J}_{\mathrm{g} 3 \mathrm{z}}-$ inertia of the gear $3\left(\mathrm{~kg} \cdot \mathrm{m}^{2}\right)$ & 0.20 \\
\hline $\mathrm{J}_{\mathrm{GNz}}-$ inertia of the generator $\left(\mathrm{kg} \cdot \mathrm{m}^{2}\right)$ & 93.22 \\
\hline $\begin{array}{l}\mathrm{k}_{\mathrm{LSSz}}-\text { torsional stiffness about } \\
\mathrm{z} \text {-axis of the LSS }(\mathrm{Nm} / \mathrm{rad})\end{array}$ & $7.19 \cdot 10^{7}$ \\
\hline $\begin{array}{l}\mathrm{k}_{\mathrm{ISz}}-\text { torsional stiffness about } \\
\mathrm{z} \text {-axis stiffness of the IS }(\mathrm{Nm} / \mathrm{rad})\end{array}$ & $1.40 \cdot 10^{7}$ \\
\hline $\begin{array}{l}\mathrm{k}_{\mathrm{HSSz}}-\text { torsional stiffness about } \\
\mathrm{z} \text {-axis of the HSS }(\mathrm{Nm} / \mathrm{rad})\end{array}$ & $0.15 \cdot 10^{7}$ \\
\hline $\begin{array}{l}\mathrm{k}_{\mathrm{rp}}, \mathrm{k}_{\mathrm{sp}}-\mathrm{stiffness} \text { of the engaging tooth } \\
\text { pairs in the low speed planetary gear } \\
\text { stage }(\mathrm{N} / \mathrm{m})\end{array}$ & $0.73 \cdot 10^{8}$ \\
\hline $\begin{array}{l}\mathrm{k}_{\mathrm{g} 12}-\text { stiffness of the engaging tooth } \\
\text { pairs in the } 1 \text { st high-speed parallel gear } \\
\text { stage }(\mathrm{N} / \mathrm{m})\end{array}$ & $2.02 \cdot 10^{9}$ \\
\hline $\begin{array}{l}\mathrm{k}_{\mathrm{g} 34}-\text { stiffness of the engaging tooth } \\
\text { pairs in the 2nd high-speed parallel } \\
\text { gear stage }(\mathrm{N} / \mathrm{m})\end{array}$ & $0.11 \cdot 10^{8}$ \\
\hline $\mathrm{r}_{\mathrm{c}}-$ radius of carrier $(\mathrm{mm})$ & 270 \\
\hline$r_{p}-$ radius of planet $(\mathrm{mm})$ & 160 \\
\hline $\mathrm{r}_{\mathrm{s}}-\operatorname{radius}$ of $\operatorname{sun}(\mathrm{mm})$ & 110 \\
\hline $\mathrm{r}_{\mathrm{g} 1}-$ radius of gear $1(\mathrm{~mm})$ & 290 \\
\hline$r_{\mathrm{g} 2-1}-$ radius of gear $2 \_1(\mathrm{~mm})$ & 95 \\
\hline$r_{\mathrm{g} 2-2}-$ radius of gear $2 \_2(\mathrm{~mm})$ & 185 \\
\hline$r_{\mathrm{g} 3}-$ radius of gear $3(\mathrm{~mm})$ & 80 \\
\hline$\alpha$ - pressure angle $\left(^{\circ}\right)$ & 20 \\
\hline Gear ratio & 34.654 \\
\hline
\end{tabular}

The vibrations are up and down according to 0 -axis line until $27 \mathrm{sec}$. On the way, irregular vibration is shown and the reference axis is moved from $27 \mathrm{sec}$. These phenomenon come from the coupled motion. If the system does not coupled each other, we cannot see the similarity between each dynamic result. The irregular vibration should be considered in more details, but we can find the same time point which similar vibration happen in Figure 3. Particularly, there are symmetric vibrations between gear mesh parts and same vibrations between the two parts which are connected by shaft. [17-18]

When the drive-train operates, the stiffness matrix changes. If there is a problem including system defects, the stiffness matrix has singular values or components which can occur non-symmetry or noninvertible. This fact makes sense with Figure 3. Unlike steady gear mesh model, variable gear mesh gives abnormal motions. Abnormal motions affect not only system behavior, but also gear mesh contact force. So, it is necessary to see phenomenon about gear mesh contact force and analyze causes of abnormal motions. 

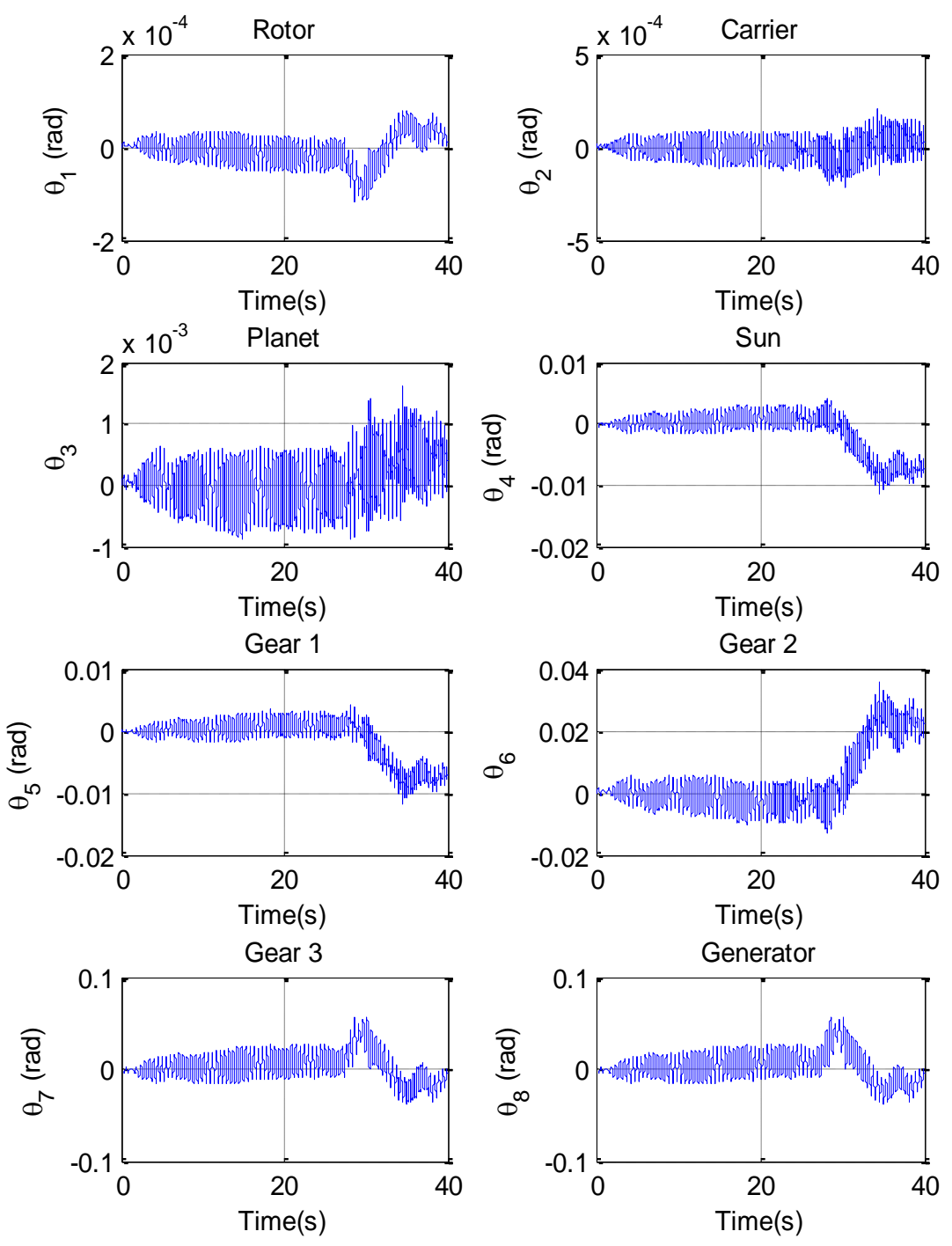

Figure 3. Angular displacement difference between variable gear mesh and steady gear mesh model.

\subsection{Contact force comparison}

The gear mesh contact force takes place when two gear teeth meet and fall away repeatedly. According to gear geometry or type, the definition of contact force can be different. Generally, it derived by angular displacement and gear mesh stiffness. As shown previously, variable gear mesh model affects angular displacement. In other words, it affects the gear mesh contact force directly.

Figure 4 shows the gear mesh contact force. There are some characteristics. First, two models have characteristic frequencies. Variable gear mesh has arbitrary frequency not the same as steady gear mesh. This phenomenon comes from angular displacement. In the steady gear mesh model, each gear's angular displacement has regular intervals which means vibrations in Figure 4. However, it doesn't make sense in real operations. Particularly, irregular gear mesh happens frequently, when each gear's angular velocity goes fast.

The second characteristic is magnitude of gear mesh. Variable gear mesh model shows no rules for magnitude of gear mesh. Especially, it does not have the gear mesh frequency. Although gear mesh stiffness's phase is different, mesh stiffness's magnitude ranges are same. This fact shows that angular displacement give sensitive effects on the gear mesh contact force. This fact can be well-shown by Figure 3 .

Regarding analyzing in frequency domain, gear mesh frequencies disappears in Figure 5. Instead of the gear mesh frequency, there are lots of small peaks which seem like noises in the range of 0-10 Hz. As each rotor has not constant angular velocity, the gear mesh is not periodic. In other words, gears meet irregularly, 
so the gear mesh frequency should not be shown in Figure 5. However, the result with the steady gear mesh shows mesh frequencies. Even though angular velocity of the gear is not steady, the steady gear mesh cannot show real meshing, because it is modelled with specific angular velocity. Consequently, the gear mesh contact force that is function of time and angular displacement respectively, makes different plots in Figure 5. Table 2 shows how differences in gear mesh affect dynamic results.

As previously stated, variable gear mesh is function of angular displacement. In other words, gear mesh is defined by angular displacement. Actually, when an external torque applies to the rotor, each angular displacement doesn't increase steadily. Gear mesh and torsional shaft stiffness make rotational delay or fast. In contrast to the steady gear mesh, variable gear mesh interacts more on angular displacement. As shown in Table. 2, each step of the angular displacement, velocity, and acceleration are function of previous values. Of course, $\Delta \mathrm{u}, \Delta \mathrm{v}$, and $\Delta \mathrm{a}$ are also added by previous step $\mathrm{u}, \mathrm{v}$ and a in steady gear mesh model. However, these $\Delta$ values are not exactly considered. In the Newmark method, every terms is determined by the Taylor series and assumption of linearization of acceleration. If we use steady gear mesh, it means that the Newmark conditions are not satisfied. Through these facts, it is imperative to include variable gear mesh concept to get exact solution.
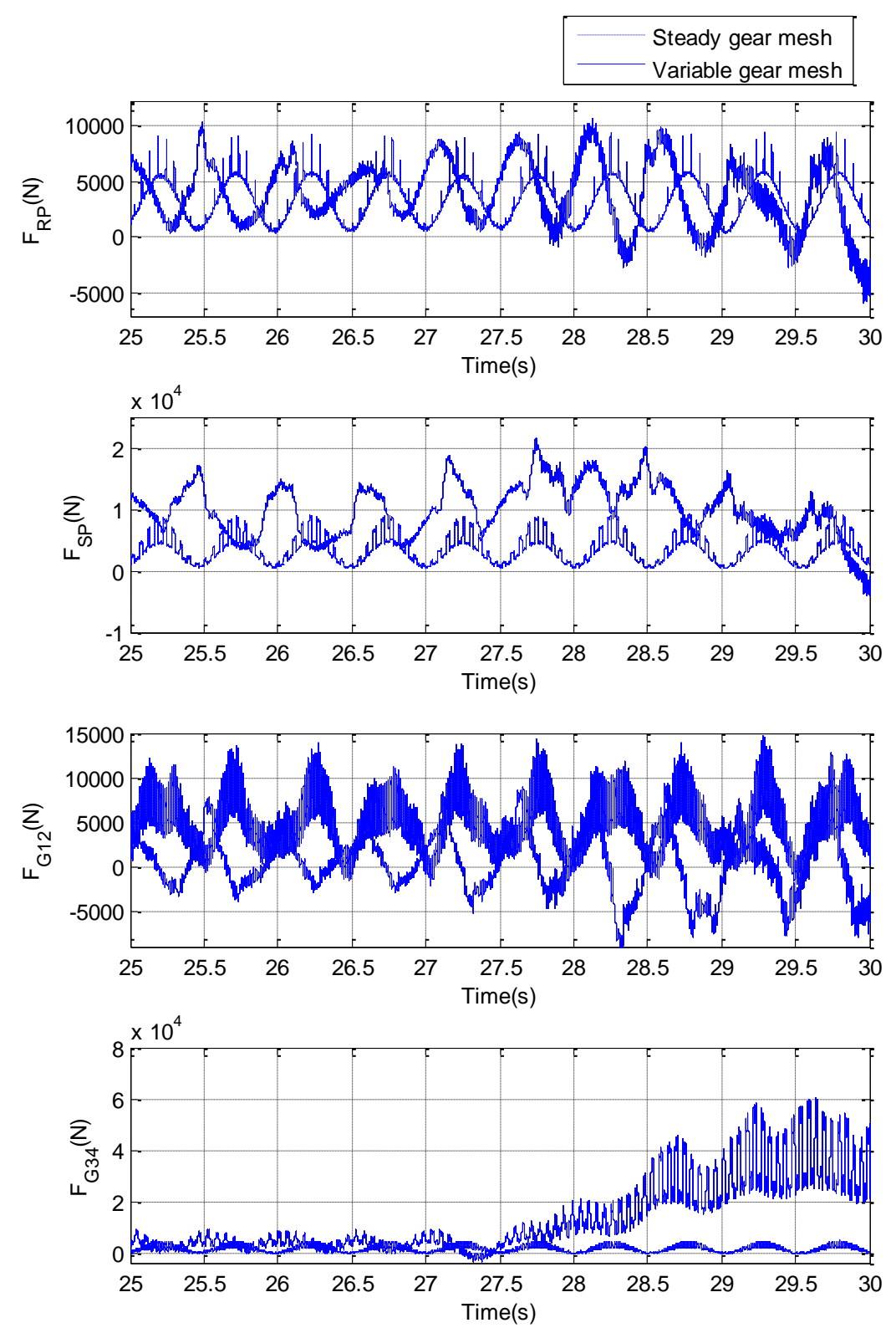

Figure 4. Angular displacement difference between the variable gear mesh and steady gear mesh model. 

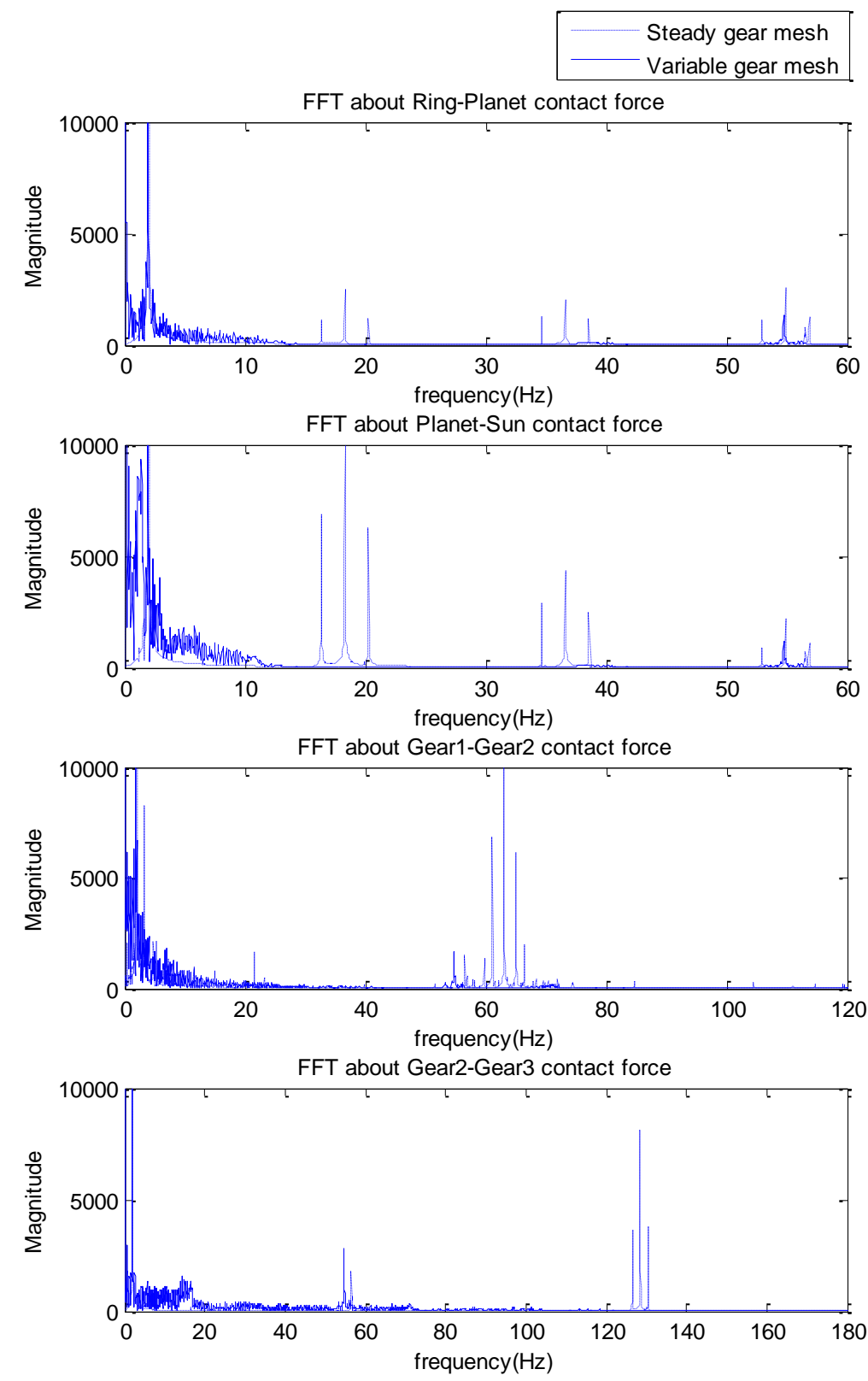

Figure 5. Fourier transformation about gear mesh contact force.

Table 2. Gear mesh function effect on the system.

\begin{tabular}{|c|c|c|}
\hline & Steady gear mesh & Variable gear mesh \\
\hline Variable of gear mesh & $t$ & $\theta=\omega t$ \\
\hline Effective stiffness & $K_{\mathrm{eff}}=K_{\mathrm{eff}}(t)$ & $K_{\mathrm{eff}}=K_{\mathrm{eff}}(\theta)$ \\
\hline \multirow{2}{*}{ Numerical Analysis } & \multicolumn{2}{|c|}{$\left.\Delta v=\frac{\gamma}{\beta \Delta t} \Delta u-\frac{\gamma}{\beta} v_{i}+\left(\Delta t\left(1-\frac{\gamma}{2 \beta}\right)\right) a_{i} \Delta a=\frac{1}{\beta \Delta t^{2}} \Delta u-\frac{1}{\beta \Delta t} v_{i}-\left(\frac{1}{2 \beta}\right)\right) a_{i}$} \\
\hline Angular displacement, & $\Delta u=f(t)$ & $\Delta u=f(\theta)$ \\
velocity, acceleration & $\Delta v=f^{\prime}(t)$ & $\Delta v=f^{\prime}(\theta) \frac{\partial \theta}{\partial t} \Delta a=f^{\prime \prime}(\theta) \frac{\partial \theta}{\partial t}+f^{\prime}(\theta) \frac{\partial^{2} \theta}{\partial t^{2}}$ \\
\hline
\end{tabular}




\section{Conclusion}

Gear mesh is one of the main characteristics in the drive-train. This affects the system by composing stiffness matrix. In previous work, the gear mesh model was considered by the function of constant angular velocity. It was used in the steady-state analysis which is designed to see results in a short time. However, this assumption doesn't make sense from the real operation. This is because the transient analysis considers arbitrary environments such as variable angular velocity to get the real response.

In this research, we suggested variable gear mesh model. It was derived by converting previous gear mesh stiffness model from constant angular velocity and time concept to angular displacement concept. Through this process, we obtained the complicated dynamic results. It is hard to give exact physical meaning but, we showed which factor makes such results and behaviors trend. As angular velocity goes fast, the gear mesh contact force goes irregular and is concentrated on particular values which are defined by the angular displacement.

Using this gear mesh concept, we can expand it to 3-dimensional or applied model. Especially, the aerodynamic torque it depends on the wind velocity and blade's drag, lift position. It means that the external force which applies rotor is not constant. Therefore, it should be researched by combining detailed torque and a drive train model including variable gear mesh in the future.

\section{Nomenclature}

$T=$ Kinetic energy

$V=$ Potential energy

$L=$ Lagrange equation

$N=$ Gear ratio

$C_{r p}, C_{r s}=$ Gear contact ratio

$\gamma_{r p}=$ Planet Gear's gear mesh angle

$q=$ Generalized coordinate

$[\mathrm{J}]=$ Mass matrix

$[K]=$ Stiffness matrix

$[C]=$ Damping matrix

$[Q]=$ Generalized force

$\Phi=$ Degree of freedom

\section{References}

[1] Shi, W., Kim, C. W., Chung, C. W., Park, H. C.: Dynamic Modeling and Analysis of a Wind Turbine Drivetrain Using the Torsional Dynamic Model, International Journal of Precision Engineering and Manufacturing, 14 (2013), 1, 153-159.

[2] Shi, W., Park, Y. H., Park, H. C., Ning, D. Z.: Dynamic analysis of the wind turbine drivetrain considering shaft bending effect, Journal of Mechanical Science and Technology, 32 (2018), 7, 30653072.

[3] Todorov, M., Vukov, G.: Parametric torsional vibrations of a drive train in horizontal axis wind turbine, Proceeding of 1st conference Franco-Syrian about renewable energy, Damas, Syrie, 2010, 1-17.

[4] Zhang, Q., Kang, J., Dong, W., Lyu, S.: A study on tooth modification and radiation noise of manual transaxle, International Journal of Precision Engineering and Manufacturing, 13 (2012), 6, 1013-1020.

[5] Shlecht, B., Shulze, T., Rosenlocher, T.: Simulation of heavy drive trains with multimegawatt transmission power in SimPACK, SIMPACK Users Meeting, Kurhaus, Baden-Baden Germany, 2006.

[6] Todorov, M., Vukov, G.: Modal Properties of Drive Train in Horizontal-Axis Wind Turbine, Romanian Review Precision Mechanics, Optics \& Mechatronics, 40 (2011), 267-275.

[7] Lee, D. H., Hodges, D. H., Patil, M. J.: Multi-flexible-body Dynamic Analysis of Horizontal Axis Wind Turbines, Wind Energy, 5 (2002), 4, 281-300.

[8] Juvinal, C. R., Marshek, K. M.: Fundamentals of Machine Component Design, 4th Edition, Wiley, New York, 2006.

[9] van der Lunden, F. L. J., de Souza Silva, P. V.: Modelling and Simulating the Efficiency and Elasticity of Gearboxes, Proceedings 7th Modelica Conference, Como, Italy, 2009, 270-277. 
[10] Wang, J., Qin, D., Ding, Y.: Dynamic Behavior of Wind Turbine by a Mixed Flexible-Rigid Multi-Body Model, Journal of System Design and Dynamics, 3 (2009), 3, 403-419.

[11] Shabana, A. A.: Computational Dynamics, John Wiley \& Sons, New York, 2010.

[12] Chopra, A. K., Dynamics of structures, Prentice Hall, New Jersey, 1980.

[13] Nikravesh, P. E.: Planar multibody dynamics formulation, programming, and applications, CRC Press, Florida, 2007.

[14] Kim, Y. D., Kim, C. W.,, Lee, S. J., Park, H. C.: Dynamic Modeling and Numerical Analysis of a Cold Rolling Mill, International Journal of Precision Engineering and Manufacturing, 14 (2013), 3, 407-413.

[15] Chapra, S. C., Canale, R. P.: Numerical methods for engineers with personal computer applications, McGraw-Hill, New York, 1987.

[16] Bathe, K. J.: Finite element procedures, Klaus-Jurgen Bathe, Cambridge, 2006.

[17] Rao, S. S.: Mechanical Vibrations, 4th ed., Prentice Hall, New Jersey 2004.

[18] Craig, R. R., Kurdila, A. J.: Fundamentals of structural dynamics, John Wiley \& Sons, New York, 2006. 